\title{
Behavioural Risk Factors of Noncommunicable Diseases among Nepalese Urban Poor: A Descriptive Study from a Slum Area of Kathmandu
}

\author{
Natalia Oli, ${ }^{1}$ Abhinav Vaidya, ${ }^{1}$ and Gobardhan Thapa ${ }^{2}$ \\ ${ }^{1}$ Department of Community Medicine, Kathmandu Medical College, Sinamangal, Kathmandu, Nepal \\ ${ }^{2}$ Kathmandu Medical College, Sinamangal, Kathmandu, Nepal
}

Correspondence should be addressed to Natalia Oli; olinatalia@hotmail.com

Received 14 February 2013; Accepted 10 September 2013

Academic Editor: Ana Marice Ladeia

Copyright (C) 2013 Natalia Oli et al. This is an open access article distributed under the Creative Commons Attribution License, which permits unrestricted use, distribution, and reproduction in any medium, provided the original work is properly cited.

\begin{abstract}
There has been a rapid rise in the burden of noncommunicable diseases in low-income countries like Nepal. Political and economical instability leading to internal migration give rise to haphazard urbanization in Nepal. This, coupled with negative effects of globalization, is largely responsible for changing lifestyle and developing risky behaviour among the urban poor that put them at high risk of developing noncommunicable diseases. A descriptive cross-sectional quantitative study was conducted from September to December 2012 in an urban slum of Kathmandu to explore the prevalence of four major behaviour risk factors namely physical inactivity, low fruit and vegetable consumption, and tobacco and alcohol use and to measure the burden of obesity and hypertension in the population. We used WHO NCDs Risk Factor steps 1 and 2 questionnaires in all the 689 households of the slum. The major behavioral risk factors for noncommunicable diseases were very common with at least a quarter of the population having the major risk factors. The results may serve to form a framework to future planning, policy-making, implementation, and evaluation of any measures undertaken to reduce these risk factors, especially as the government is planning to unveil the National Urban Health Policy soon.
\end{abstract}

\section{Introduction}

It is well established that noncommunicable diseases (NCDs) are the leading cause of adult mortality and morbidity worldwide including the Southeast Asia region (SEAR) [1]. Four main NCDs, namely cardiovascular diseases (CVDs), diabetes, cancers, and chronic respiratory diseases, are mainly responsible for this high mortality and morbidity. Of the estimated 14.5 million total deaths in 2008 in SEAR, more than half $(55 \%)$ of them were due to NCDs, mainly cardiovascular disease (25\%) [1].

From the beginning, NCDs and particularly CVDs were termed diseases of the rich in the developed countries [2]. However, over the past two decades, CVD deaths have been declining in the high-income countries but increasing significantly in the low- and middle-income countries (LMICs) [3]. One of the reasons for this increase is the rising life expectancy like the one being seen in South Asia region which leads to shifting disease burden towards NCDs [4]. Moreover, at the same time, the trend of urbanization is drastically increasing in this region causing changes in lifestyle of the people. For example, shifting lifestyle towards low physical activity and unhealthy diet leads to a rise in prevalence of obesity and NCDs among urban population [5]. For this reason, NCDs have also been called "diseases of urbanization". Risk factors of NCDs such as high blood pressure are found more commonly among urban communities compared to rural in the developing countries [6].

In 2008, half of the world's population lived in urban areas and if this trend continues, 70 percent of the global population will be living in urban areas by 2050 [7]. No doubt that one of the negative impacts of this demographic transition is formation of slum and squatter settlements in the urban area. UN-HABITAT has estimated some 38 percent of the LMIC population lives in slums with 433 million of them living in Asia [8]. Slum communities are defined as a wide range of low-income settlements with inadequate living conditions and substandard facilities. The residents of 
slums areas generally own their land and house and have formal title papers. On the other hand, squatter settlements are those communities where people have settled on land without any legal right to be there. But as the patterns of living in both these settlements are similar, the term slum is often used to describe both. The urban poor have the most disadvantageous position among all the urban population. This is because they adopt urban lifestyle that put them at a higher risk of developing NCDs and at the same time, lack of knowledge and information regarding health, poor access to healthcare, and poor economic status worsen the situation among them [6].

Nepal is not an exception in regard to urbanization. According to the national census 2011, about 17 percent of the total Nepalese population live in urban areas [9]. Most of the urban population is concentrated in the capital Kathmandu and its rapid growth has led to increasing pressure in Kathmandu. At present, there are 63 slum and squatter settlements in Kathmandu, and their population is estimated to be growing by 25 percent per year [10]. Most of the slums settlements are located in the centre of the city along the river banks of Bagamati, Bishnumati, and Manohara Rivers. People in slum areas have high levels of health risks and problems due to inadequate water supply, basic sanitation, and proper nutrition, amongst others.

Facing the epidemiological transition like many LMICs, Nepal is also experiencing double burden of communicable and noncommunicable diseases [11]. CVDs are the most common cause of NCD admissions in Nepal (38\%) according to a 2010 hospital-based study [12]. It is well known that up to $80 \%$ of heart disease, stroke, and type 2 diabetes and over a third of cancers could be prevented by eliminating common risk factors, mainly tobacco use, unhealthy diet, physical inactivity, and the harmful use of alcohol [13]. These unhealthy behaviours lead to metabolic changes such as raised blood pressure, obesity, raised blood sugar, and lipids. Moreover, coexistence of modifiable behavioural and metabolic risk factors in the same person increases the individual's total risk of developing acute vascular events such as heart attacks and strokes [3].

Studies and interventions in the Nepalese slums deal mainly with communicable diseases, environmental, and sanitation problems, while NCDs have remained largely neglected $[10,14-16]$. Thus, very little is known about the spectrum and burden of NCD morbidity in the Nepalese slum population. Because people from slum do come to hospitals with late complications of NCDs, it is obvious that NCDs exist among urban poor as well [17, 18]. Reasons for this late presentation could be their low health seeking behaviour due to lack of health knowledge and information and poor purchasing ability [17].

A number of studies have been conducted in Nepal using WHO steps risk factors questionnaire in different urban and rural areas [19]. These studies have however eluded slum and squatters areas. Hence, we undertook the present study to measure the prevalence of four major behaviour risk factors, namely physical inactivity, low fruit and vegetable consumption, and tobacco and alcohol use, in a slum population of Kathmandu. Additionally, we also aimed to find out the level

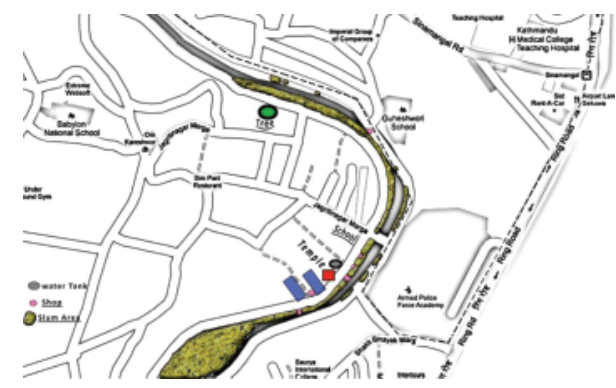

FIgURE 1: Map of the Sinamangal slum area, Kathmandu. The study area is shown as the shaded area (yellow) along the banks of the river (grey) across the middle of the map.

of two major physical risk factors, obesity, and hypertension, in this study.

\section{Methods}

2.1. Study Site and Population. The study was of descriptive cross-sectional quantitative design. It was conducted in the Sinamangal squatter area in Kathmandu Metropolitan City along the banks of Bagmati River, from September to December 2012 (Figure 1). The study area was purposively selected because it is a predefined study area for Family Health Advisory Programme for medical students under the Department of Community Medicine, Kathmandu Medical College. The study area is about one kilometre away from the medical college. As the squatter area has settlements scattered both upstream and downstream, the area of the squatter settlement falling in the Sinamangal area was first demarcated. It was then arbitrarily divided into four clusters.

The study population included household members aged 15-64 years living for at least 6 months in the defined squatter area and who consented to participate in the study. Because there was no official information about the number of households in the squatter area to construct a sampling frame, nonprobability convenient sampling technique was used.

2.2. Data Collection. Data was collected by third-year medical students of Kathmandu Medical College. The eighty medical students were divided in to four groups of 20 for each of the four clusters. The students were trained by the researchers in taking informed consent, administering questionnaire, interview techniques, and physical measurements. Each household was visited and the person available at that time was interviewed. If nobody was present in the household during the first visit, the student revisited it again at the time when the resident of the house would be available.

If there was more than one eligible respondent in a household, a lottery method was used to select one respondent. The students were continuously supervised by the researchers during the data collection process.

\subsection{Study Tools}

2.3.1. Questionnaire. Data was collected through face-toface interviews using questions based on WHO NCD risk 
factor steps 1 and 2 questionnaires [20]. Biochemical measurements of step 3 were not performed because of logistic limitations. The questionnaire included questions regarding demographic characteristic of the respondents, tobacco and alcohol consumption, physical activity, and fruit and vegetable consumption.

2.3.2. Physical Measurements. Height, weight, waist, and hip circumferences were measured. The instructions given in the step 2 were followed while taking the measurements. Weight was measured with Microlife BR-9201 weighing machine (Microlife AG Swiss Corporation, Widnau, Switzerland). Height, waist, and hip circumferences were measured with nonstretchable measuring tapes (Jonson Tapes Ltd., New Delhi, India). Aneroid sphygmomanometers (Doctor Aneroid Sphygmomanometer, Japan) were used for blood pressure recording. Blood pressure was recorded three times with a gap of 5 minutes between the recordings. Average of the three readings was taken as the final blood pressure measurement.

2.3.3. Operational Definitions. The definitions used for the study were based on the WHO steps survey manual and are briefly described below [20]. Occupation and educational categories are also based on the WHO steps survey manual. Classification of ethnic group is based on the National Central Bureau of Statistics of Nepal [9]:

(a) current drinkers: respondents who consumed alcohol in the previous 30 days;

(b) one serving of vegetable: one cup of raw, leafy green vegetables (spinach, salad, etc.), one half cup of other vegetables, cooked or raw (tomatoes, pumpkin, beans etc.), or half cup of vegetable juice;

(c) one serving of fruit: one medium-sized piece of fruit (banana, apple, etc.) or half cup of raw, cooked or canned fruit, or a half cup of juice from a fruit (not artificially flavoured);

(d) physical activity: it included questions on number of days and time spent on vigorous and/or moderate activities at work, travel to and from places, and recreational activities. The responses were then converted to MET minutes/week. The respondents were labelled as having vigorous activity or moderate activity if they achieved certain MET minutes as given in the WHO steps manual. Someone was termed as having low physical activity (LBA) if s/he did not fulfil the criteria of having vigorous or moderate activity;

(e) hypertension: it included those who self-reported as having hypertension or those who had high blood pressure according to JNC-VII classification [21] during the time of survey;

(f) combined risk factors: the following risk factors were considered while counting the number of risk factors present:

(i) current daily smoker, (ii) less than 5 servings of fruits and vegetables per day,

(iii) low physical activity ( $<600$ MET minutes),

(iv) overweight or obese (BMI $\geq 25 \mathrm{~kg} / \mathrm{m}^{2}$ ),

(v) raised $\mathrm{BP}$ (SBP $\geq 140$ and/or DBP $\geq 90 \mathrm{mmHg}$ or currently on medication for raised $\mathrm{BP}$ ).

2.4. Data Management and Analysis. The filled questionnaires were thoroughly checked by the researchers for any inconsistencies. Data coding and cleaning were done. Data was entered and analysed with SPSS version 20.0 (IBM, Armonk, New York, USA). Descriptive analysis was done; mean with standard deviations was calculated for continuous variables, and percentages were calculated for categorical variables.

2.5. Ethical Consideration. The study obtained approval from Ethical Review Committee of Kathmandu Medical College. All principles of Helsinki Declaration were ensured during the study. Informed consent was obtained from each participant after the objectives of study had been explained. Privacy and confidentiality were thoroughly maintained during the interview. Filled questionnaires were securely placed in the Department of Community Medicine. There were no physical risks as there was no intervention such as blood sampling done during the study. However, there was possible psychological risk due to questions related to income and personal behaviours, and the students were trained to sensitively handle them. Those who were found to have the risk factors under the study were counselled and/or referred to Kathmandu Medical College for the needful.

\section{Results and Discussion}

Altogether 689 households were identified in the defined study area and we included one person from each household; thus, we had a sample size of 689 . There were no nonresponders. Based on the response given by the respondents about the number of adults aged 15-64 years in his/her house, we calculated that there were 2356 adults of age 15-64 residing in the area. Thus, our study covered $29.24 \%$ of the adults aged 15-64 years living in the area.

3.1. Demographic Characteristics. The demographic characteristics of the study population are described in Table 1. Half of the respondents were aged less than 35 years. About $60 \%$ were women. About $40 \%$ had no formal education. About one third of the respondents were self-employed, while a quarter of the women were housewives. Thirteen percent of the respondents were unemployed though they were able to work. Majority $(72.3 \%)$ of them had been staying there for more than five years. More than one third of the respondents had a monthly income of less than NRs. 5000 (1 US Dollar = approximately 85 Nepalese Rupees). Most of them had come to live in the squatter because of economic reasons, in search of a job, because of natural calamities like flood in their native places, or due to marriage. They had migrated mainly from other parts of Kathmandu district (22\%), or from 
TABle 1: Demographic characteristics of the study population $(N=689)$. Classification of ethnic group is based on the National Central Bureau of Statistics [9]. Primary and secondary schooling indicate education up to grades 4 and 10, respectively. Other ethnic group includes Terai Dalit, disadvantaged Janajatis (Terai), disadvantaged non-Dalit Terai caste groups, and religious minorities. Other occupations include nonpaid, retired, and unemployed ones (unable to work).

\begin{tabular}{|c|c|c|c|c|c|c|}
\hline & \multicolumn{2}{|c|}{ Male } & \multicolumn{2}{|c|}{ Female } & \multicolumn{2}{|c|}{ Total } \\
\hline & $N$ & $\%$ & $N$ & $\%$ & $N$ & $\%$ \\
\hline \multicolumn{7}{|l|}{ Age (years) } \\
\hline $15-24$ & 75 & 26.5 & 117 & 28.8 & 192 & 27.9 \\
\hline $25-34$ & 56 & 19.8 & 109 & 26.8 & 165 & 23.9 \\
\hline $35-44$ & 61 & 21.6 & 87 & 21.4 & 148 & 21.5 \\
\hline $45-54$ & 48 & 17.0 & 53 & 13.1 & 101 & 14.7 \\
\hline $55-64$ & 29 & 10.2 & 23 & 5.7 & 52 & 7.5 \\
\hline$\geq 65$ & 14 & 4.9 & 17 & 4.2 & 31 & 4.5 \\
\hline \multicolumn{7}{|l|}{ Ethnicity } \\
\hline Hill Dalit & 33 & 11.7 & 66 & 16.3 & 99 & 14.4 \\
\hline Disadvantaged Janajatis (Hill) & 113 & 39.9 & 185 & 45.6 & 298 & 43.3 \\
\hline Relatively advantaged Janajatis & 34 & 12.0 & 30 & 7.4 & 64 & 9.3 \\
\hline Upper caste groups & 89 & 31.4 & 112 & 27.6 & 201 & 29.2 \\
\hline Others & 14 & 49 & 13 & 3.2 & 27 & 3.9 \\
\hline \multicolumn{7}{|l|}{ Highest education } \\
\hline No formal education & 71 & 25.1 & 209 & 51.5 & 280 & 40.6 \\
\hline Less than primary & 27 & 9.5 & 19 & 4.7 & 46 & 6.7 \\
\hline Primary completed & 109 & 38.5 & 106 & 26.1 & 215 & 31.2 \\
\hline Secondary completed & 58 & 20.5 & 55 & 13.5 & 113 & 16.4 \\
\hline High school or more & 18 & 6.4 & 17 & 4.2 & 35 & 5.1 \\
\hline \multicolumn{7}{|l|}{ Occupation } \\
\hline Employed (government/nongovernment) & 59 & 20.8 & 32 & 7.9 & 90 & 13.1 \\
\hline Self-employed & 137 & 48.4 & 109 & 26.8 & 246 & 35.7 \\
\hline Student & 21 & 7.4 & 38 & 9.4 & 59 & 8.6 \\
\hline Housewife & 0 & 0.0 & 159 & 39.2 & 163 & 23.7 \\
\hline Unemployed (able to work) & 46 & 16.3 & 45 & 11.1 & 89 & 12.9 \\
\hline Others & 20 & 7.1 & 23 & 5.7 & 42 & 6.1 \\
\hline \multicolumn{7}{|l|}{ Migration (years) } \\
\hline$<1$ & 28 & 9.9 & 38 & 9.4 & 66 & 9.6 \\
\hline $1-5$ & 43 & 15.2 & 82 & 20.2 & 125 & 18.1 \\
\hline $5-10$ & 98 & 34.6 & 139 & 34.2 & 237 & 34.4 \\
\hline$>10$ & 114 & 40.3 & 147 & 36.2 & 261 & 37.9 \\
\hline \multicolumn{7}{|l|}{ Income status (NRs) $(n=391)$} \\
\hline 1st quartile $(\leq 5000)$ & 55 & 27.9 & 91 & 46.9 & 146 & 37.3 \\
\hline 2nd quartile (5001-7000) & 32 & 16.2 & 35 & 18.0 & 67 & 17.1 \\
\hline 3rd quartile (7001-10000) & 51 & 25.9 & 42 & 21.6 & 93 & 23.8 \\
\hline 4th quartile $(\geq 10000)$ & 59 & 29.9 & 26 & 13.4 & 85 & 21.7 \\
\hline
\end{tabular}

NRs: Nepalese rupees.

other nearby districts such as Kavrepalanchok (6\%) and Sindhupalchowk (3\%), or from Eastern Nepal districts such as Sindhuli (10\%), Jhapa (7\%), and Morang (5\%).

3.2. Behavioural Risk Factors. The urban poor remain neglected part of urban population in terms of exploring their burden of behaviour risk factors and prevalence of NCDs among them. During the present study, it was found that the four important behavioural risk factors of NCDs-tobacco consumption, harmful use of alcohol, low fruit and vegetable consumption, and physical inactivity-are rampant in the slum population. Moreover, hypertension and obesity are also prevalent in the study population.

3.2.1. Tobacco Consumption. Age-sex distribution of smoking is presented in Figure 2. Prevalence of smoking in men, women, and both sexes is $51.9 \%, 24.1 \%$, and $35.6 \%$. The overall (both sexes) prevalence of smoking in the present study is higher than the national data (23.8\%) [19]. The smoking rate in the population is higher than that in the urban population 


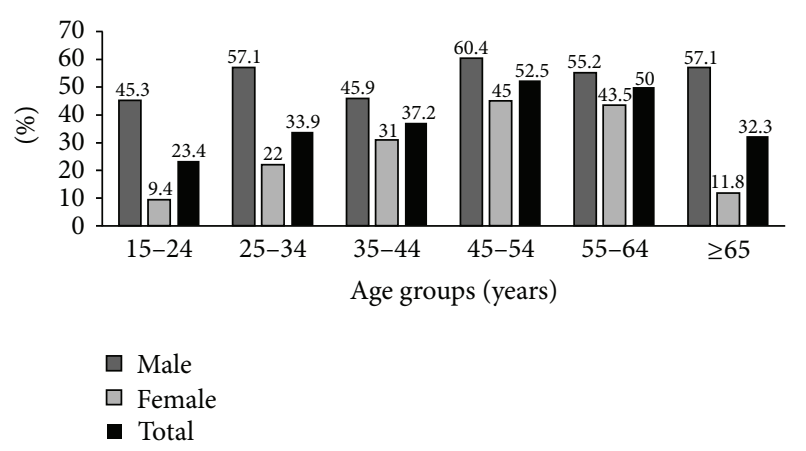

Figure 2: Prevalence (\%) of current smokers in the study population according to the age group $(n=689)$. The categories are based on the WHO NCD risk factor steps survey manual [20]. Current smokers included those who responded "yes" to "Do you smoke?". Dark and light grey bars are for men and women, respectively, while the black bars represent both sexes.

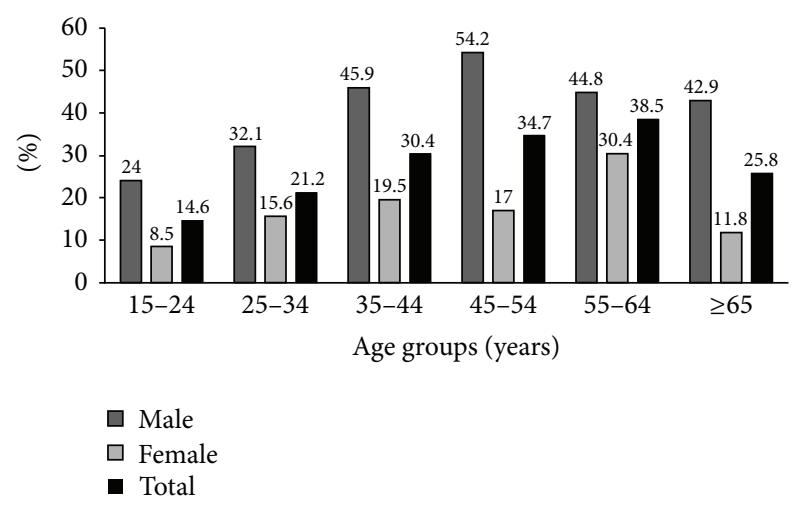

FIgURE 3: Prevalence (\%) of current Smokeless tobacco in the study population according to the age group $(n=689)$. The categories are based on the WHO NCD risk factor steps survey manual [20]. Smokeless tobacco included products such as gutka, khaini, and surti. Dark and light grey bars are for men and women respectively, while the black bars represent both sexes.

of Myanmar (22.0\%) [22] and the Chennai (20.2\%) [23] and Patna (12.54\%) [24] slums of India but lower than that in the Mumbai slum (66.7\%) [18]. But compared to the urban poor from Kerala, India, there is not a large difference (37.3\%) [25].

By gender-wise stratification also, more men and women in our study smoke compared to the of the Nepal's national data $(31.2 \%$ and $15.5 \%)$ [19], the urban population of Myanmar (44.8 and 7.8\%) [22], and the urban slum of Patna (21.15\% and 5.91\%) [24]. Comparatively, fewer women (12.2\%) and more men (62.6\%) in the Kerala slum smoked [25].

Regarding smokeless tobacco, the overall consumption rate in our study is $24.8 \%$ (men: $38.5 \%$, women: $15.3 \%$ ). Agesex distribution of smokeless tobacco is shown in Figure 3. Compared to the national figures (18.6\% for both sexes, $31.2 \%$ for men, and $4.6 \%$ for women), prevalence of consumption of smokeless tobacco is also higher in the study population [19]. The figures are however less compared to data from India and Myanmar. There are twice more consumers (55.4\%) in the Mumbai slum [18] than in our study. Similarly, the prevalence

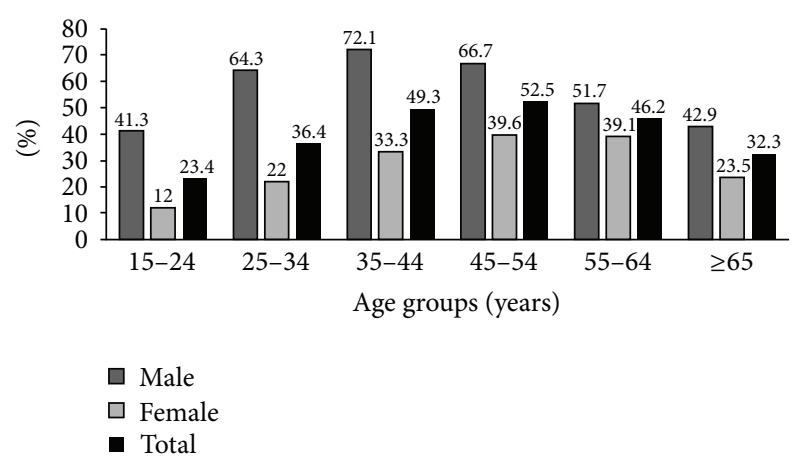

FIGURE 4: Prevalence (\%) of current drinkers in the study population according to the age group $(n=689)$. The categories are based on the WHO NCD risk factor steps survey manual [20]. Current drinkers refer to the ones that consumed alcohol within the previous month. Dark and light grey bars are for men and women, respectively, while the black bars represent both sexes.

in the urban Myanmar is also higher with 51.4\% of the males and $16.1 \%$ of females consuming smokeless tobacco [22].

It is already an established fact that tobacco consumption is now universally more common among lower socioeconomic groups. For example, prevalence of tobacco chewing among women labourers in Dharan, Nepal (22\%), was twice as much as among service class women (10\%) [26].

3.2.2. Alcohol Consumption. Alcohol consumption in the slum is very high with $38.5 \%$ of the study population $(58 \%$ of men and $24.9 \%$ of women) being current drinkers, that is, who had alcohol containing drink in the last 30 days. Among the current drinkers, one third consumes it daily (men: $34.6 \%$, women: $31.1 \%)$. Comparatively, less people (31.2\%) in the Mumbai slum drank [18]. Age-sex distribution of current drinkers is shown in Figure 4. Prevalences of alcohol consumption in the males and females of the study area were higher than the national averages for men (39.3\%) and women (16.5\%) [19]. Among males, the current drinking rate is higher than that in their counterparts from Patna (16.65\%) [24] and Kerala (45.4\%) [25]. The highest prevalence of current drinking was seen in the 35-44 years age group (72.1\%). Similarly, more females in the Sinamangal slum drink more than the women of Patna slum (3.35\%) [24] and in Kerala slum (1.0\%) [25].

3.2.3. Fruits and Vegetable Consumption. The mean fruit consumption was less than two days per week with about $20 \%$ taking fruits less than once a week (Table 2). Comparatively, vegetable consumption was better with average six days per week. A higher level of fruit and vegetable intake has been observed among the urban slum dwellers in Chennai where more than half population consumed vegetables 5 days and fruits 3 days per week [27]. The mean number of servings of fruit and/or vegetables per day in the present study was lowone serving per day for fruits and two servings per day for vegetables (Table 2). Myanmar urban slum population had better fruit and vegetable consumption [22].

More than five servings of fruit and vegetables are recommended for healthy living, but $90.5 \%$ men and $93.3 \%$ 
TABLE 2: Fruit and vegetable consumption in the study population $(N=689)$. One serving of fruit means one medium-sized piece of fruit (banana, apple, etc.) or half cup of raw, cooked or canned fruit, or a half cup of juice from a fruit (not artificially flavoured). One serving of vegetable is one cup of raw, leafy green vegetables, (spinach, salad, etc.), one half cup of other vegetables, cooked or raw (tomatoes, pumpkin, beans, etc.), or half cup of vegetable juice.

\begin{tabular}{|c|c|c|c|c|c|c|}
\hline & \multicolumn{2}{|c|}{ Male } & \multicolumn{2}{|c|}{ Female } & \multicolumn{2}{|c|}{ Total } \\
\hline & $N$ & $\%$ & $N$ & $\%$ & $N$ & $\%$ \\
\hline \multicolumn{7}{|c|}{ Fruit consumption } \\
\hline \multicolumn{7}{|l|}{ Days/week } \\
\hline 0 & 60 & 21.2 & 79 & 19.5 & 139 & 20.2 \\
\hline $1-3$ & 181 & 64.0 & 272 & 67.0 & 453 & 65.7 \\
\hline $4-6$ & 29 & 10.2 & 42 & 10.3 & 71 & 10.3 \\
\hline 7 & 13 & 4.6 & 13 & 3.2 & 26 & 3.8 \\
\hline Mean (SD) & \multicolumn{2}{|c|}{$1.96(1.76)$} & \multicolumn{2}{|c|}{$1.94(1.66)$} & \multicolumn{2}{|c|}{$1.95(1.70)$} \\
\hline \multicolumn{7}{|l|}{ Servings/day } \\
\hline 0 & 60 & 21.2 & 79 & 19.5 & 139 & 20.2 \\
\hline $1-2$ & 204 & 72.1 & 312 & 76.8 & 516 & 74.9 \\
\hline$\geq 3$ & 19 & 6.7 & 15 & 3.7 & 34 & 4.9 \\
\hline Mean (SD) & \multicolumn{2}{|c|}{$1.08(0.81)$} & \multicolumn{2}{|c|}{$1.03(0.72)$} & \multicolumn{2}{|c|}{$1.05(0.76)$} \\
\hline \multicolumn{7}{|c|}{ Vegetable consumption } \\
\hline \multicolumn{7}{|l|}{ Days/week } \\
\hline 0 & 4 & 1.4 & 9 & 2.2 & 13 & 1.9 \\
\hline $1-3$ & 26 & 9.2 & 38 & 9.4 & 64 & 9.3 \\
\hline $4-6$ & 82 & 29.0 & 104 & 25.4 & 186 & 27.0 \\
\hline 7 & 171 & 60.4 & 255 & 62.8 & 426 & 61.8 \\
\hline Mean (SD) & \multicolumn{2}{|c|}{$6.01(1.59)$} & \multicolumn{2}{|c|}{$5.95(1.72)$} & \multicolumn{2}{|c|}{$5.98(1.67)$} \\
\hline \multicolumn{7}{|l|}{ Servings/day } \\
\hline 0 & 4 & 1.4 & 9 & 2.2 & 13 & 1.9 \\
\hline $1-2$ & 250 & 88.3 & 354 & 87.2 & 604 & 87.7 \\
\hline$\geq 3$ & 29 & 10.2 & 43 & 10.6 & 72 & 10.4 \\
\hline Mean (SD) & \multicolumn{2}{|c|}{$1.80(0.84)$} & \multicolumn{2}{|c|}{$1.73(0.97)$} & \multicolumn{2}{|c|}{$1.76(0.92)$} \\
\hline \multicolumn{7}{|c|}{ Combined fruit and vegetable } \\
\hline \multicolumn{7}{|l|}{ Servings } \\
\hline$<5$ & 256 & 90.5 & 379 & 93.3 & 635 & 92.2 \\
\hline$\geq 5$ & 27 & 9.5 & 27 & 6.7 & 54 & 7.8 \\
\hline Mean (SD) & \multicolumn{2}{|c|}{$2.88(1.32)$} & \multicolumn{2}{|c|}{$2.76(1.33)$} & \multicolumn{2}{|c|}{$2.81(1.33)$} \\
\hline
\end{tabular}

SD: standard deviation.

women consume less than the recommended five servings of fruit and vegetables daily in the study area. The situation in the slum is worse compared to the average Nepalese data according to which $60.5 \%$ of men and $63.5 \%$ of women have inadequate fruit and vegetable consumption [19]. Our study population fared worse in comparison to other studies in the similar settings as well $[22,25,27]$. Low consumption of fruits and vegetables in the urban poor can be due to lack of health knowledge, poor economic status of urban poor, and preference for junk food that put them at high risk of developing NCDs.

3.2.4. High Salt Containing Food Consumption. About $14 \%$ of the respondents are taking high salt containing food such as chips, instant noodles, and pickles every day. While a quarter of the respondents are taking such food less than once a week or 1-2 times in a week, about $17 \%$ almost never had them.
3.2.5. Level of Physical Inactivity. One third of the study population in the slum have low physical activity. This contrasts with the lower prevalence of physical inactivity across Nepal (5.9\%) [19] or the Kerala slum (4.5\%) [25] but may be considered less compared to the very high physical inactivity Chennai figure of 95\% [23]. The data is however similar to the one from the Patna slum (33.64\%) [24].

Prevalence of low physical activity in the Sinamangal slum is higher in the females (39.4\%) than in the males $(21.9 \%)$. In fact, the women here are more inactive than those from Patna and Kerala slum settlements $(37.65 \%$ and $4.9 \%$, resp.) $[24,25]$. At the same time, fewer males in the present study were physically inactive in contrast with $30.55 \%$ of males in the Patna slum [24]. Furthermore, low physical activity increased drastically from the average of $20 \%$ in the younger age group to around $60 \%$ in those aged 65 or more (Table 3). Those employed either in the government 
TABLE 3: Prevalence (\%) of low physical activity in the study population according to demographic variables $(N=689)$. The physical activity section included questions on number of days and time spent on vigorous and/or moderate activities at work, travel to and from places, and recreational activities. The responses were then converted to MET minutes/week. The respondents were labelled as having vigorous activity or moderate activity if they achieved certain MET minutes as given in the WHO steps manual [20]. Someone was termed as having low physical activity (LBA) if s/he did not fulfil the criteria of having vigorous or moderate activity.

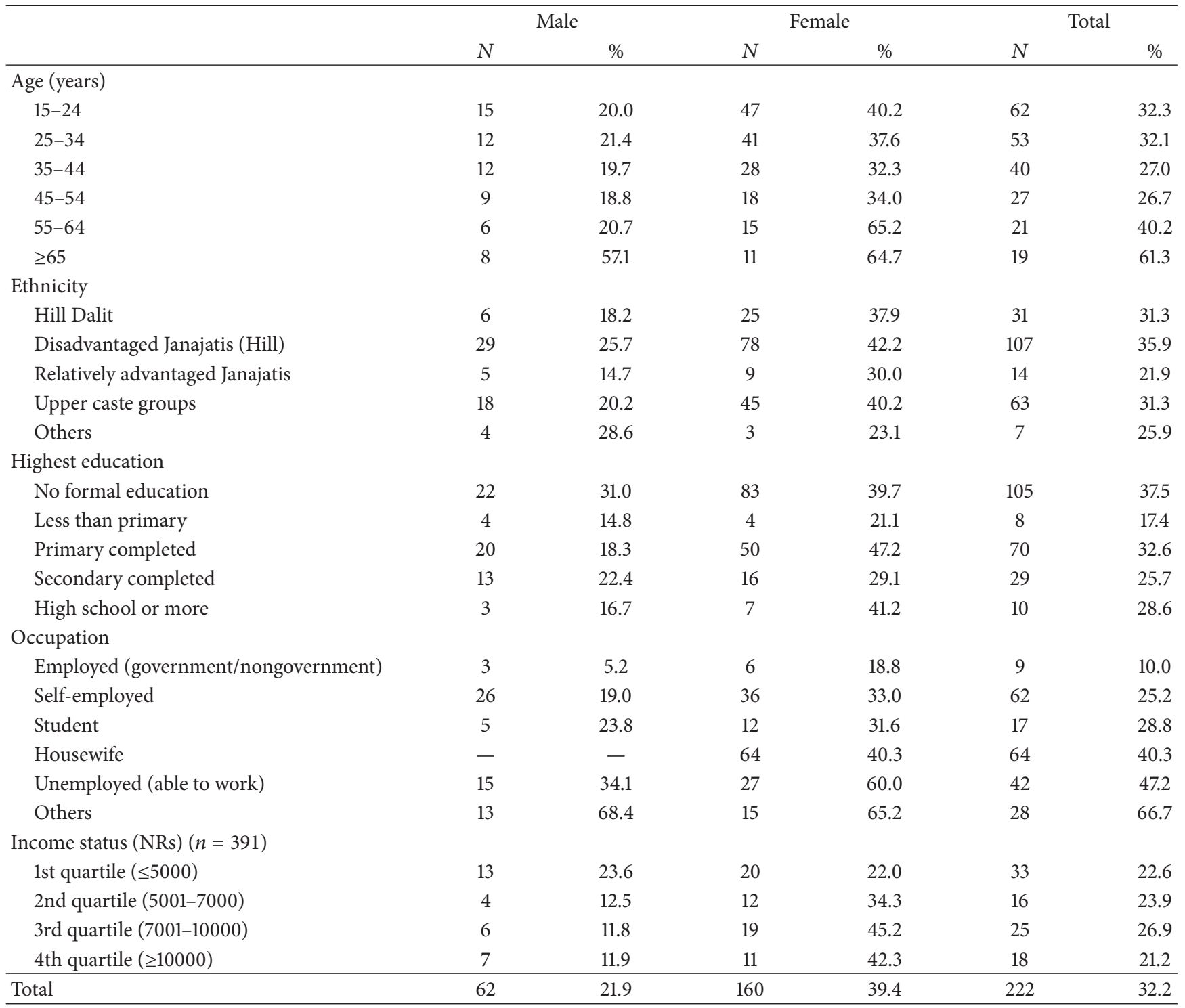

NRs: Nepalese rupees.

or nongovernmental organizations had less prevalence of low physical activity (10\%). Whereas both men and women belonging to the lowest income group had similar prevalence of low physical activity, the women with high income tended to become less physically active compared to men of the same income group.

3.2.6. Blood Pressure Status. A respondent who was either a known hypertensive or was found to have high blood pressure during the survey was called having "hypertension." Twentyeight percent of the respondents are thus found to have hypertension (Table 4). This prevalence is higher than the national average (21.5\%) [19]. It is also high compared to the
Indian slums of Chennai (22.8\%) [23] and Patna (16.36\%) [24]. On the other hand, the Kerala slum has a slightly higher (31\%) prevalence of high blood pressure [25].

Prevalence of hypertension according to various demographic variables is given in Table 4 . The males have a higher prevalence of hypertension (35.0\%) than the females (23.2\%). In fact, hypertension prevalence in the males of the slum is higher than the national average of $24.5 \%$ [19] and the urban males of Dharan town in the Eastern Nepal (22.7\%) [28]. Furthermore, the prevalence rates are even higher than some of the slums of India such as Patna (18.79\%) [24] and Kerala (31.0\%) [25] but lower than the very high figure of Mumbai (71.2\%) [18]. Though women in the slum had 
TABLE 4: Prevalence of hypertension in the study population according to demographic variables $(N=689)$. Hypertensives included those who self-reported as having hypertension or those who had high blood pressure according to JNC-VII classification [21] during the time of survey.

\begin{tabular}{|c|c|c|c|c|c|c|}
\hline & \multicolumn{2}{|c|}{ Male } & \multicolumn{2}{|c|}{ Female } & \multicolumn{2}{|c|}{ Total } \\
\hline & $N$ & $\%$ & $N$ & $\%$ & $N$ & $\%$ \\
\hline \multicolumn{7}{|l|}{ Age (years) } \\
\hline $15-24$ & 11 & 14.7 & 7 & 6.0 & 18 & 9.4 \\
\hline $25-34$ & 12 & 21.4 & 17 & 15.6 & 29 & 17.6 \\
\hline $35-44$ & 26 & 42.6 & 34 & 39.1 & 60 & 40.5 \\
\hline $45-54$ & 24 & 50.0 & 18 & 34.0 & 42 & 41.6 \\
\hline $55-64$ & 18 & 62.1 & 11 & 47.8 & 29 & 55.8 \\
\hline$\geq 65$ & 8 & 57.1 & 7 & 41.2 & 15 & 48.4 \\
\hline \multicolumn{7}{|l|}{ Ethnicity } \\
\hline Hill Dalit & 14 & 42.4 & 12 & 18.2 & 26 & 26.3 \\
\hline Disadvantaged Janajatis (Hill) & 39 & 34.5 & 47 & 25.4 & 86 & 28.9 \\
\hline Relatively advantaged Janajatis & 13 & 38.2 & 12 & 40.0 & 25 & 39.1 \\
\hline Upper caste groups & 30 & 33.7 & 20 & 17.9 & 50 & 24.9 \\
\hline Others & 3 & 21.4 & 3 & 23.1 & 6 & 22.2 \\
\hline \multicolumn{7}{|l|}{ Highest education } \\
\hline No formal education & 34 & 47.9 & 61 & 29.2 & 95 & 33.9 \\
\hline Less than primary & 7 & 25.9 & 2 & 10.5 & 9 & 19.6 \\
\hline Primary completed & 34 & 31.2 & 20 & 18.9 & 54 & 25.1 \\
\hline Secondary completed & 16 & 27.6 & 8 & 14.5 & 24 & 21.2 \\
\hline High school or more & 8 & 44.4 & 3 & 17.6 & 11 & 31.4 \\
\hline \multicolumn{7}{|l|}{ Occupation } \\
\hline Employed (government/nongovernment) & 20 & 34.5 & 3 & 9.4 & 23 & 25.6 \\
\hline Self-employed & 49 & 35.8 & 30 & 27.5 & 79 & 32.1 \\
\hline Student & 3 & 14.3 & 3 & 7.9 & 6 & 10.2 \\
\hline Housewife & - & - & 37 & 23.3 & 37 & 23.3 \\
\hline Unemployed (able to work) & 16 & 36.4 & 12 & 26.7 & 28 & 31.5 \\
\hline Others & 11 & 57.9 & 9 & 39.1 & 20 & 47.6 \\
\hline \multicolumn{7}{|l|}{ Migration (years) } \\
\hline$<1$ & 5 & 17.9 & 4 & 10.5 & 9 & 13.6 \\
\hline $1-5$ & 20 & 46.5 & 16 & 19.5 & 36 & 28.8 \\
\hline $5-10$ & 32 & 32.7 & 31 & 22.5 & 63 & 26.6 \\
\hline$>10$ & 42 & 36.8 & 43 & 29.3 & 85 & 32.6 \\
\hline \multicolumn{7}{|l|}{ Income status (NRs) $(n=391)$} \\
\hline 1st quartile $(\leq 5000)$ & 15 & 27.3 & 18 & 19.8 & 33 & 22.6 \\
\hline 2nd quartile (5001-7000) & 13 & 40.6 & 10 & 28.6 & 23 & 34.3 \\
\hline 3rd quartile (7001-10000) & 21 & 41.2 & 10 & 23.8 & 31 & 33.3 \\
\hline 4 th quartile $(\geq 10000)$ & 21 & 35.6 & 8 & 30.8 & 29 & 34.1 \\
\hline Total & 99 & 35.0 & 94 & 23.2 & 193 & 28.0 \\
\hline
\end{tabular}

NRs: Nepalese rupees.

less hypertension compared to men, it was still high in comparison to the Nepalese average (18.1\%) [19] and the Patna slum (14.48\%) [24].

Blood pressure status of the population according to extent of awareness, treatment, and control is presented in Figure 5 . About $63 \%$ of the study population had their blood pressure measured in the previous 12 months while $34.7 \%$ of the males and $29.8 \%$ of the females never had their blood pressure checked. Among the latter group, $49 \%$ of the males (i.e., $17 \%$ of the total male respondents) and $24.8 \%$ of the females (i.e., $7.4 \%$ of the total female respondents) were found to have high blood pressure during the survey - that is, undiagnosed hypertension. This prevalence of undiagnosed hypertension among both sexes in our study was about $20 \%$ which is higher than that in the Chennai slum study (15.4\%) [23]. Likewise, our male population also had slightly higher prevalence of undiagnosed hypertension compared to the Dharan study (17\% versus 14.4\%) [28].

In our study, $17.6 \%$ males and $15.8 \%$ females were known hypertensives-among whom $50 \%$ males (i.e., $8.8 \%$ 


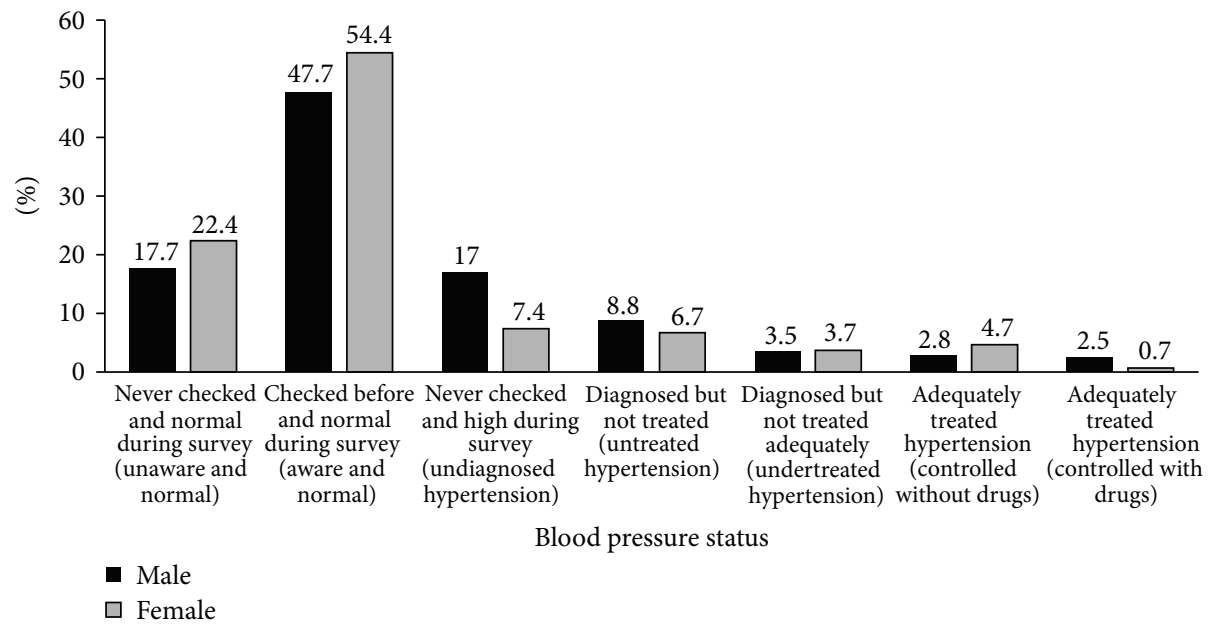

FIGURE 5: Blood pressure status of the study population according to different sub-categories of awareness, treatment and control $(N=$ 689). Hypertensives included those who self-reported as having hypertension or those who had high blood pressure according to JNC-VII classification [21] during the time of survey. Black bars are for men and grey bars are for women respectively.

of total male respondents) and $42.4 \%$ (i.e., $6.7 \%$ of total female respondents) were untreated-that is, diagnosed but untreated hypertension. Among the hypertensive population who were receiving treatment, $39.8 \%$ of the males and $40.7 \%$ of the females still had high blood pressure during the survey-that is, $3.5 \%$ of the total male respondents and $3.7 \%$ of the total female respondents had undertreated hypertension. The remaining hypertensives had their blood pressure under control-that is, $5.3 \%$ of the total male respondents or $30.1 \%$ of the male hypertensives, and $5.4 \%$ of the total female respondents or $34.2 \%$ of the female hypertensives had their blood pressure under control with or without drugs. The control rate among the known male hypertensive population was less in our study compared to the study in the Dharan (30.1\% versus $58.5 \%)$ [28].

3.2.7. General and Abdominal Obesity. According to their body mass index, almost one quarter of the respondents (26.0\% of males and $23.9 \%$ of females) were overweight, while $5.8 \%$ were obese (Table 5 ). In the males, prevalence of overweight was the highest in the 35-44 years group (37.7\%) while females had the highest percent $(28.4 \%)$ of overweight in the 25-34 years group (Table 5). Ethnicitywise, relatively advantaged Janajatis had the highest prevalence of overweight and obesity, while the prevalence was less in those who had studied more than secondary education and who were currently students. In terms of abdominal obesity, females had higher waist circumference across all demographic parameters than males (Table 5).

Unlike the other slum studies from India, the problem of high BMI is found to be more in males than in females in our study population. For example, the prevalence of overweight women was higher than men in the urban Myanmar (13.5\% males and 22\% females) [22] and in Kerala slums (men$29.7 \%$, women-41\%) [25]. Even in the Mumbai slum settlement, though $42.1 \%$ males were overweight compared to
$11.7 \%$ females, $20 \%$ of women were obese in contrast to $0.8 \%$ males [18].

3.2.8. Combination of Risk Factors. About forty percent of the males and thirty percent of the females had 3-5 risk factors (Table 6). This is much higher than the $12.5 \%$ and $5.8 \%$ in the national representative data of Nepal [19]. In our study, the upper caste groups had the least occurrence of " $3-5$ risk factors" in both males and females. Those who were selfemployed or were unemployed despite being able to work and those without formal education had more risk factors. Similarly, those who had lived for a longer time in the slum area were found to have more risk factors compared to those who had recently migrated. There was no definite relationship between income and number of risk factors.

3.3. Strengths and Limitations of the Study. Our study explored NCD risk factors in an urban slum for the first time in Nepal. Through this study, we intended to measure the status of NCD risk factors in this population group, so that appropriate recommendations could be made to improve any prevalent risk factors. We followed the WHO STEPwise approach to surveillance which is a standardized method for collecting, analysing, and disseminating data in WHO member countries. Data collection was done by trained medical students under continuous supervision of medical faculty. During the course of data collection, any needy respondent was referred to the hospital for further management ensuring that the study incorporated socioethical values.

Our study had certain limitations and weaknesses. There were disproportionately more women respondents $(60 \%)$ in our study. Although there is no actual demographic data to compare if the male:female ratio is different in the population, unintentional oversampling of women is possible as the data collection was done during daytime when many 
TABLE 5: Prevalence (\%) of overweight and obesity, increased waist circumference, and increased waist hip ratio according to demographic variables $(n=689)$. Increased waist circumference is waist measurements of $\geq 80 \mathrm{~cm}$ for females and $\geq 90 \mathrm{~cm}$ for males; increased waist hip ratio is $\geq 0.85$ for females and $\geq 0.90$ for males. Income status data is only for 391 persons who disclosed their financial information.

\begin{tabular}{|c|c|c|c|c|c|c|c|c|}
\hline & \multicolumn{4}{|c|}{ Body mass index } & \multicolumn{2}{|c|}{$\begin{array}{l}\text { Increased waist } \\
\text { circumference }\end{array}$} & \multicolumn{2}{|c|}{$\begin{array}{l}\text { Increased waist } \\
\text { hip ratio }\end{array}$} \\
\hline & \multicolumn{2}{|c|}{ Overweight $\left(25-29.9 \mathrm{~kg} / \mathrm{m}^{2}\right)$} & \multicolumn{2}{|c|}{ Obesity $\left(\geq 30 \mathrm{~kg} / \mathrm{m}^{2}\right)$} & \multirow[b]{2}{*}{ Male } & \multirow[b]{2}{*}{ Female } & \multirow[b]{2}{*}{ Male } & \multirow[b]{2}{*}{ Female } \\
\hline & Male & Female & Male & Female & & & & \\
\hline \multicolumn{9}{|l|}{ Age (years) } \\
\hline $15-24$ & 8.0 & 9.4 & 5.3 & 0.9 & 10.7 & 17.1 & 49.3 & 54.7 \\
\hline $25-34$ & 28.6 & 28.4 & 0.0 & 3.7 & 14.3 & 45.9 & 50.0 & 59.6 \\
\hline $35-44$ & 37.7 & 25.3 & 11.5 & 8.0 & 32.8 & 51.7 & 63.9 & 71.3 \\
\hline $45-54$ & 31.2 & 24.5 & 8.3 & 9.4 & 27.1 & 56.6 & 60.4 & 69.8 \\
\hline $55-64$ & 17.2 & 26.1 & 3.4 & 4.3 & 37.9 & 43.5 & 58.6 & 34.8 \\
\hline$\geq 65$ & 28.6 & 17.6 & 7.1 & 5.9 & 35.7 & 52.9 & 71.4 & 52.9 \\
\hline \multicolumn{9}{|l|}{ Ethnicity } \\
\hline Hill Dalit & 21.2 & 16.9 & 6.1 & 3.0 & 18.2 & 40.9 & 39.4 & 48.5 \\
\hline Disadvantaged Janajatis (Hill) & 26.5 & 23.6 & 6.2 & 4.3 & 21.2 & 43.2 & 58.4 & 65.9 \\
\hline Relatively advantaged Janajatis & 32.4 & 30.8 & 8.8 & 13.3 & 29.4 & 43.3 & 70.6 & 60.0 \\
\hline Upper caste groups & 20.2 & 25.3 & 4.5 & 4.5 & 23.6 & 34.8 & 53.9 & 58.9 \\
\hline Others & 21.4 & 36.4 & 7.1 & 0 & 28.6 & 38.5 & 64.3 & 53.8 \\
\hline \multicolumn{9}{|l|}{ Highest education } \\
\hline No formal education & 21.1 & 25.8 & 9.9 & 6.2 & 26.8 & 49.8 & 59.2 & 60.8 \\
\hline Less than primary & 37.0 & 21.1 & 7.4 & 0 & 18.5 & 47.4 & 59.3 & 57.9 \\
\hline Primary completed & 22.0 & 27.7 & 4.6 & 5.7 & 16.5 & 31.1 & 54.1 & 62.3 \\
\hline Secondary completed & 15.5 & 12.5 & 3.4 & 0 & 22.4 & 29.1 & 56.9 & 56.4 \\
\hline High school or more & 61.1 & 17.6 & 5.6 & 0 & 55.6 & 11.8 & 55.6 & 58.8 \\
\hline \multicolumn{9}{|l|}{ Occupation } \\
\hline Employed (government/nongovernment) & 29.3 & 25.9 & 5.2 & 6.2 & 27.6 & 34.4 & 53.4 & 59.4 \\
\hline Self-employed & 28.5 & 21.6 & 8.0 & 7.3 & 23.4 & 38.5 & 60.6 & 56.9 \\
\hline Student & - & 6.1 & 0 & 0 & 9.5 & 10.5 & 33.3 & 50.0 \\
\hline Housewife & - & 29.5 & - & 3.1 & - & 50.9 & - & 68.6 \\
\hline Unemployed (able to work) & 22.7 & 23.1 & 6.8 & 6.7 & 29.5 & 37.8 & 59.1 & 53.3 \\
\hline Others & 15.8 & 22.2 & 0 & 4.3 & 10.5 & 39.1 & 52.6 & 52.2 \\
\hline \multicolumn{9}{|l|}{ Migration } \\
\hline$<1$ & 14.3 & 17.1 & 3.6 & 0 & 17.9 & 26.3 & 25.0 & 50.0 \\
\hline $1-5$ & 25.6 & 25.6 & 9.3 & 8.5 & 23.3 & 41.5 & 72.1 & 61.0 \\
\hline $5-10$ & 28.6 & 21.4 & 5.1 & 5.7 & 21.4 & 38.8 & 58.2 & 63.3 \\
\hline$>10$ & 22.8 & 25.4 & 6.1 & 3.2 & 25.4 & 44.9 & 57.0 & 59.9 \\
\hline \multicolumn{9}{|l|}{ Income status (NRs) } \\
\hline 1st quartile $(\leq 5000)$ & 31.3 & 19.0 & 2.1 & 6.3 & 20.8 & 43.0 & 68.8 & 60.8 \\
\hline 2nd quartile (5001-7000) & 29.0 & 33.3 & 6.5 & 13.3 & 27.6 & 39.4 & 65.5 & 66.7 \\
\hline 3rd quartile (7001-10000) & 38.8 & 26.3 & 10.2 & 0.0 & 28.9 & 53.8 & 62.2 & 76.9 \\
\hline 4th quartile $(\geq 10000)$ & 32.8 & 33.3 & 8.6 & 8.3 & 29.3 & 43.5 & 60.3 & 65.2 \\
\hline Total & 26.0 & 23.9 & 6.4 & 5.3 & 25.8 & 45.1 & 63.5 & 67.3 \\
\hline
\end{tabular}

NRs: Nepalese rupees.

men may have gone for work. We tried to minimize this by visiting the households in the morning time before the men left for work. Also, we did stratified analysis for men and women to eliminate this selection bias.
Certain biological risk factors such as blood glucose and cholesterol were not included in the study due to logistic limitations. Because the sample size is moderate, only one slum area was studied and nonprobability sampling was 
TABLE 6: Summary of combined risk factors in the study population, shown in percentage $(N=689)$. The following risk factors were considered while counting the number of risk factors present: current daily smoker, less than 5 servings of fruits and vegetables per day, low physical activity ( $<600$ MET-minutes), overweight or obese (BMI $\geq 25 \mathrm{~kg} / \mathrm{m}^{2}$ ), raised BP (SBP $\geq 140$ and/or DBP $\geq 90 \mathrm{mmHg}$, or currently on medication fro raised BP [20].

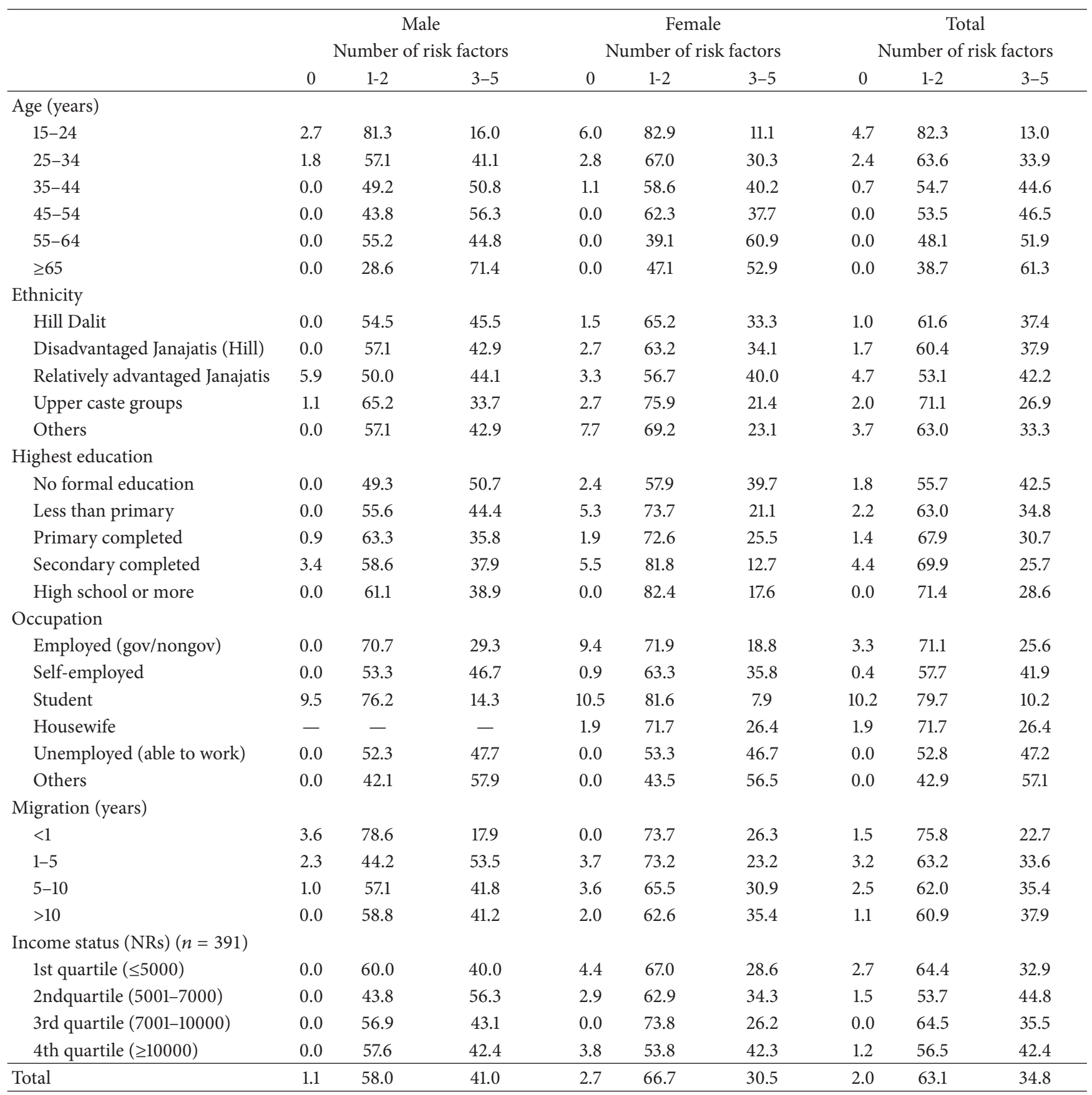

NRs: Nepalese rupees.

opted, the results may not be generalized to other slum populations.

\section{Conclusions}

NCDs are emerging as a public health problem in Nepal. Hence, surveillance of its risk factors in different population subgroups, including the urban poor, is essential for future policy making and planning by the government and other stakeholders. Our study has shown that the behavioural risk factors of NCDs are very common in the urban poor population of Kathmandu. In fact, most of the risk factors are present in at least a quarter of the slum population: smokeless tobacco, high BMI and waist hip ratio, and hypertension. Other risk factors such as tobacco smoking, current alcohol drinking, and low physical activity are found in one third 
of them. Fruit and vegetable consumption is very low with $92.2 \%$ of the population not consuming 5 or more servings. One third of the population have $3-5$ risk factors.

Health system of Nepal is based on primary health care with focus on rural health and with emphasis on communicable diseases, maternal, and child health issues including nutrition. Thus, as both urban poor population and NCDs have remained neglected by the government and other stakeholders, the urban poor are having a double jeopardy when it comes to NCDs. With such a huge burden of risk factors, even the burden of NCDs can be expected to be high among the urban poor. Tragically, though the facilities are often nearby, they cannot afford the costly diagnostic and treatment modalities that are accessible only to the higher socioeconomic stratum. Thus, in lack of access to proper promotive, preventive and curative services, and in absence of a civic system that acknowledges their existence, the slum people may therefore be suffering and dying from NCDs unnoticed and unaccounted.

Despite all this, it is indeed very heartening to note that the government has recently finalized the final draft of the National Urban Health Policy. Under this, free primary health care will be given to urban dwellers with low economic status, targeting mainly the poor living in the slum areas. We recommend that, because the slum people are probably the most severely hit population in terms of double burden of disease, the policy should give equal emphasis, if not more, to the NCDs and the underlying risk factors.

\section{Conflict of Interests}

The authors declared that there is no conflict of interests.

\section{Authors' Contribution}

The study concept was conceived by Natalia Oli. Tool preparation, training, and data collection supervision were carried out by Natalia Oli, and Abhinav Vaidya. Data entry was done by Gobardhan Thapa, Natalia Oli and Abhinav Vaidya. Data analysis was done by Abhinav Vaidya and Natalia Oli. The paper was written by Natalia Oli, Abhinav Vaidya, and Gobardhan Thapa.

\section{Acknowledgments}

The authors are highly obliged to all the participants of the study and the local leaders who facilitated conduction of the study. They are thankful to the medical students of the 13th batch of the Kathmandu Medical College for their contribution in data collection. They would also like to thank the post-graduate students, faculty members, and staff of Department of Community Medicine for their cooperation and support.

\section{References}

[1] World Health Organization, Non-Communicable Diseases in the South-East Asia Region: Situation and Response 2011, World Health Organization, New Delhi, India, 2011.
[2] D. Yach and C. Hawkes, "Chronic diseases and risks," in International Public Health, M. Merson, R. E. Black, and A. J. Mills, Eds., pp. 273-313, Jones \& Bartlett Publishers, Burlington, Mass, USA, 2006.

[3] S. Mendis, P. Puska, and B. Norrving, Global Atlas on Cardiovascular Disease Prevention and Control, World Health Organization, Geneva, Switzerland, 2011.

[4] M. M. Engelgau, S. El-Saharty, P. Kudesia, V. Rajan, and S. Rosenhouse, Capitalizing on the Demographic Transition: Tackling Noncommunicable Diseases in South Asia, World Bank Publications, 2011.

[5] A. Vaidya, S. Shakya, and A. Krettek, "Obesity prevalence in nepal: public health challenges in a low-income nation during an alarming worldwide trend," International Journal of Environmental Research and Public Health, vol. 7, no. 6, pp. 2726-2744, 2010.

[6] K. Anand, B. Shah, K. Yadav et al., "Are the urban poor vulnerable to non-communicable diseases? A survey of risk factors for non-communicable diseases in urban slums of Faridabad," National Medical Journal of India, vol. 20, no. 3, pp. 115-120, 2007.

[7] Linking Population, poverty and development, http://www .unfpa.org/pds/urbanization.htm.

[8] M. R. Montgomery and A. C. Ezeh, "The health of urban populations in developing countries," in Handbook of Urban Health, pp. 201-222, Springer, New York, NY, USA, 2005.

[9] Central Bureau of Statistics, National Population and Housing Census 2011, National Planning Commission Secretariat, 2012.

[10] CARE Nepal, Health Problems among Urban Poor in Selected Slums along Bishunumati River in Kathmandu, CARE Nepal Publications, 2008.

[11] A. Vaidya, "Tackling cardiovascular health and disease in Nepal: epidemiology, strategies and implementation," Heart Asia, vol. 3, no. 1, pp. 87-91, 2011.

[12] Nepal Health Research Council, Prevalence of Non-Communicable Disease in Nepal: Hospital-Based Study, Nepal Health Research Council, 2010.

[13] World Health Organization, 2008-2013 Action Plan for the Global Strategy for the Prevention and Control of Non-Communicable Diseases, World Health Organization, Geneva, Switzerland, 2010.

[14] "300 families screened in slums," http://www.hollows.org.au/ news-media/300-families-screened-slums.

[15] "Nepal—city slum dwellers' health condition appalling," http:// urbanhealthupdates.wordpress.com/2011/04/01/nepal-city-slumdwellers-health-condition-appalling/.

[16] "Mobile health clinics to target city slums," http://www.myrepublica.com/portal/index.php?action=news_details\&news_id= 34541.

[17] L. W. Riley, A. I. Ko, A. Unger, and M. G. Reis, "Slum health: diseases of neglected populations," BMC International Health and Human Rights, vol. 7, article 2, 2007.

[18] P. Waingankar and D. Pandit, "A cross sectional study of coronary heart disease in Urban slum population of Mumbai," International Journal of Medical and Clinical Research, vol. 3, no. 5, pp. 180-189, 2012.

[19] Ministry of Health and Population, Nepal Non-Communicable Diseases Risk Factors Survey 2007, Ministry of Health and Population, Kathmandu, Nepal, 2008.

[20] World Health Organization, WHO Steps Instrument Questionby-Question Guide (Core and Expanded), World Health Organization, Geneva, Switzerland, 2008. 
[21] A. V. Chobanian, G. L. Bakris, H. R. Black et al., "Seventh report of the joint national committee on prevention, detection, evaluation, and treatment of high blood pressure," Hypertension, vol. 42, no. 6, pp. 1206-1252, 2003.

[22] World Health Organization, Non-Communicable Disease Risk Factor Survey Myanmar 2009, World Health Organization, 2011.

[23] World Health Organization and Indian Council of Medical Research, Report of the Surveillance of Risk Factors of NonCommunicable Diseases (STEP 1 and 2) from Chennai, World Health Organization and Indian Council of Medical Research, 2002.

[24] R. Singh, M. Mukherjee, R. Kumar, and R. Pal, "Study of risk factors of coronary heart disease in Urban slums of patna," Nepal Journal of Epidemiology, vol. 2, no. 3, pp. 205-212, 2012.

[25] K. R. Thankappan, B. Shah, P. Mathur et al., "Risk factor profile for chronic non-communicable diseases: results of a community-based study in Kerala, India," Indian Journal of Medical Research, vol. 131, no. 1, pp. 53-63, 2010.

[26] S. R. Niraula, "Tobacco use among women in Dharan, Eastern Nepal," Journal of Health, Population and Nutrition, vol. 22, no. 1, pp. 68-74, 2004.

[27] A. Nath, S. Garg, S. Deb, A. Ray, and R. Kaur, "A study of the profile of behavioral risk factors of non communicable diseases in an urban setting using the WHO steps 1 approach," Annals of Tropical Medicine and Public Health, vol. 2, no. 1, pp. 15-19, 2009.

[28] A. Vaidya, P. K. Pokharel, P. Karki, and S. Nagesh, "Exploring the iceberg of hypertension: a community based study in an eastern Nepal town," Kathmandu University Medical Journal, vol. 5, no. 19, pp. 349-359, 2007. 


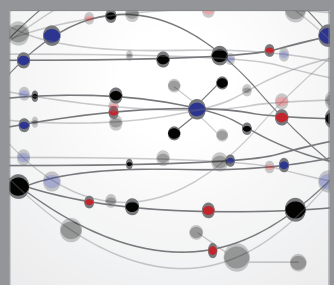

The Scientific World Journal
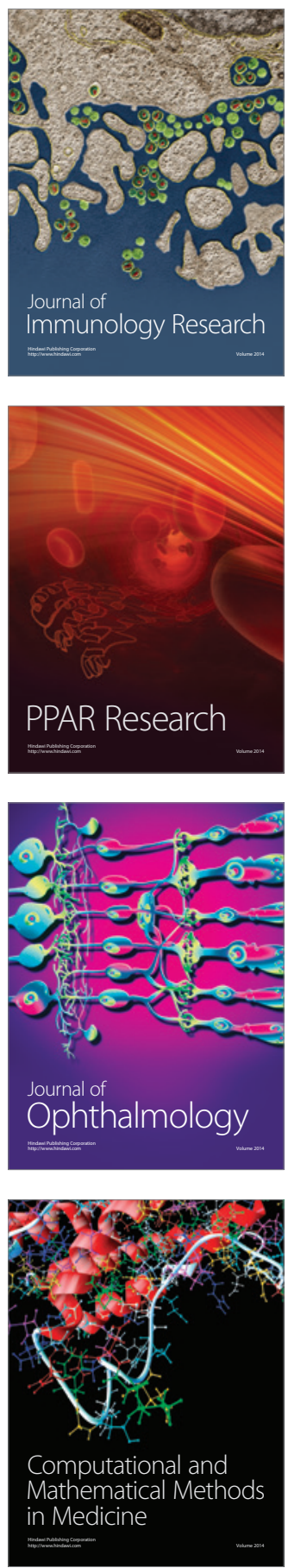

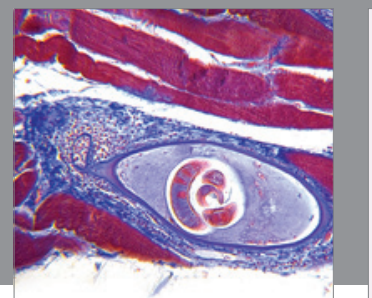

Gastroenterology

Research and Practice
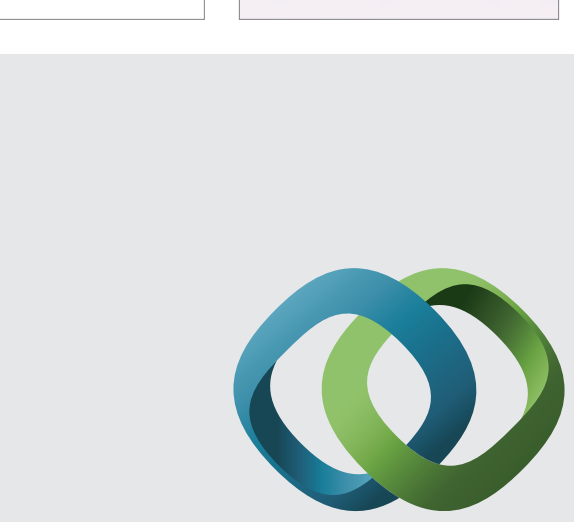

\section{Hindawi}

Submit your manuscripts at

http://www.hindawi.com
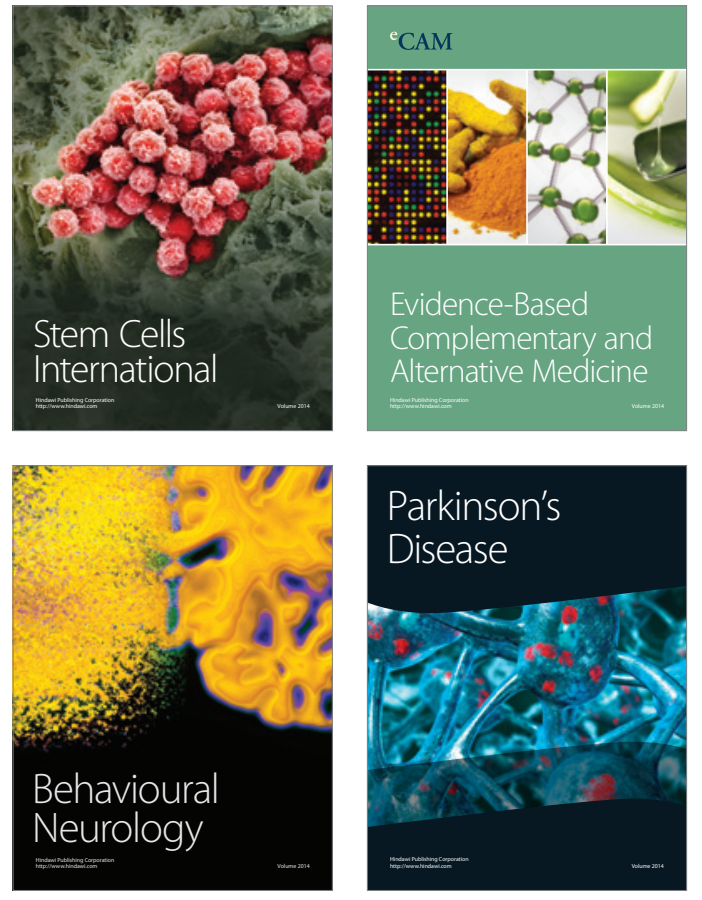
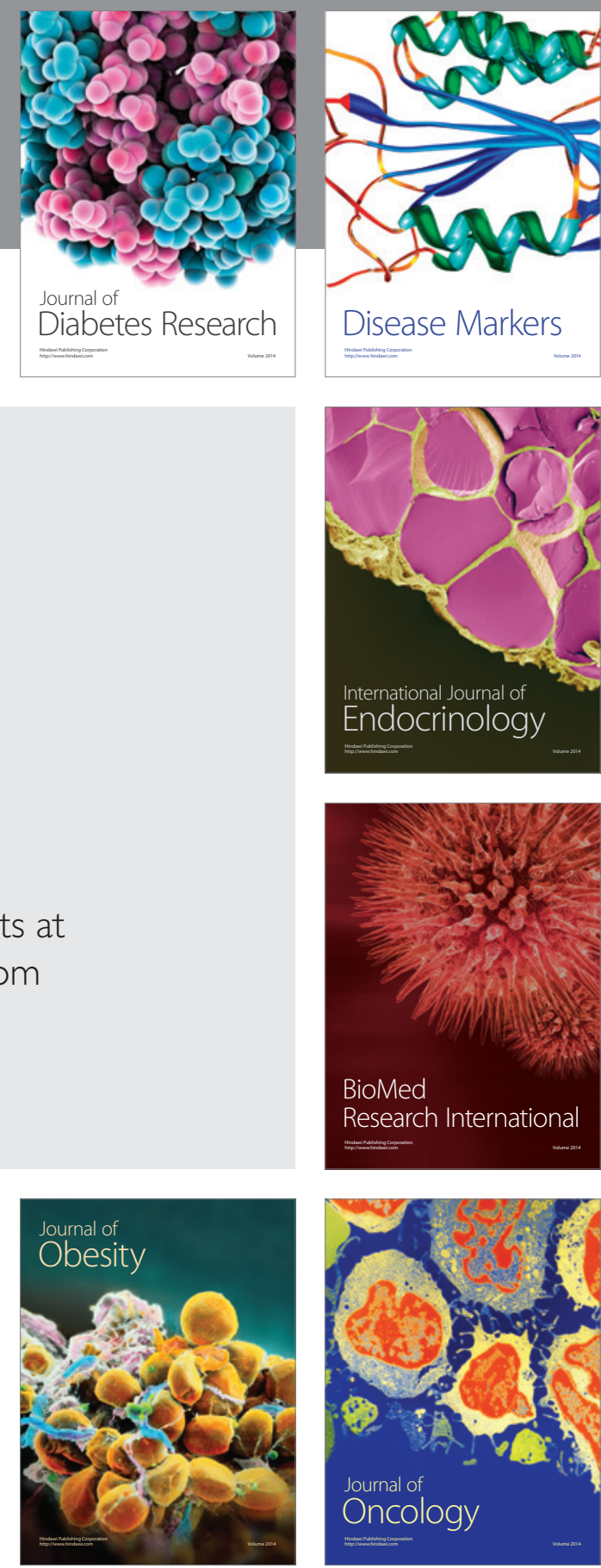

Disease Markers
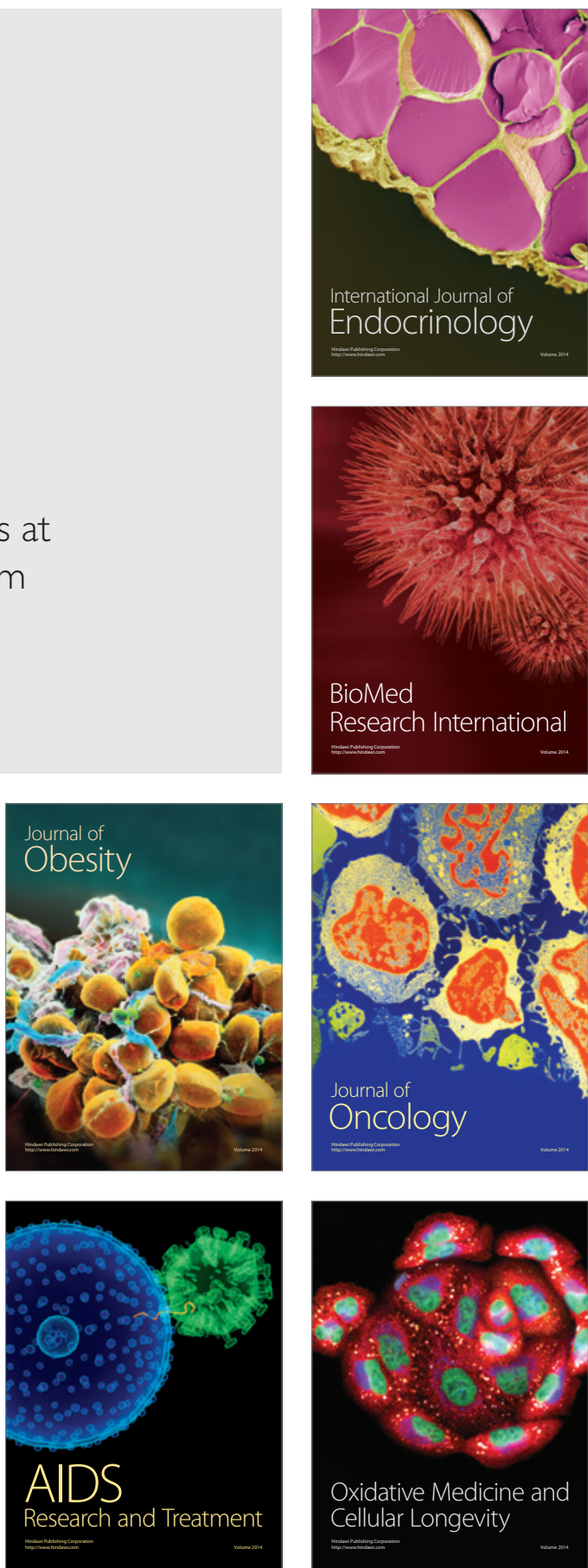